\title{
Emphysematous Gastritis in a Patient with Breast Cancer
}

\author{
Mototsugu Matsunaga ${ }^{1}$, Teruhiko Fujii ${ }^{1}$, Tomoyuki Ushijima ${ }^{1,2}$ and Keisuke Miwa ${ }^{1}$
}

Key words: emphysematous gastritis, breast cancer

(Intern Med 54: 1667-1668, 2015)

(DOI: 10.2169/internalmedicine.54.4415)

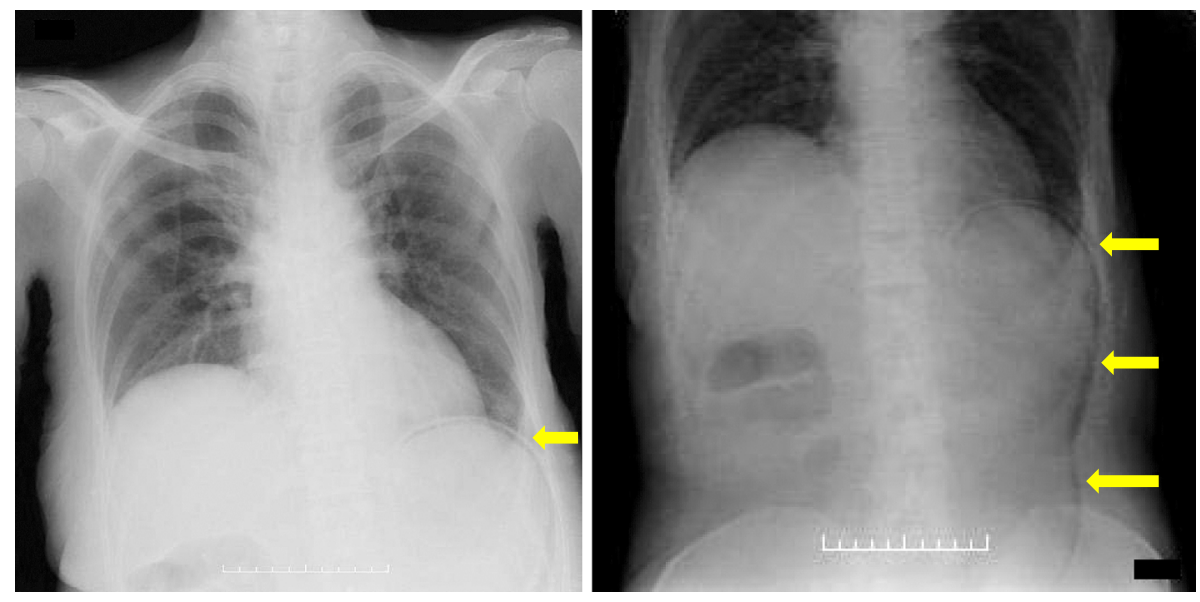

Picture 1.
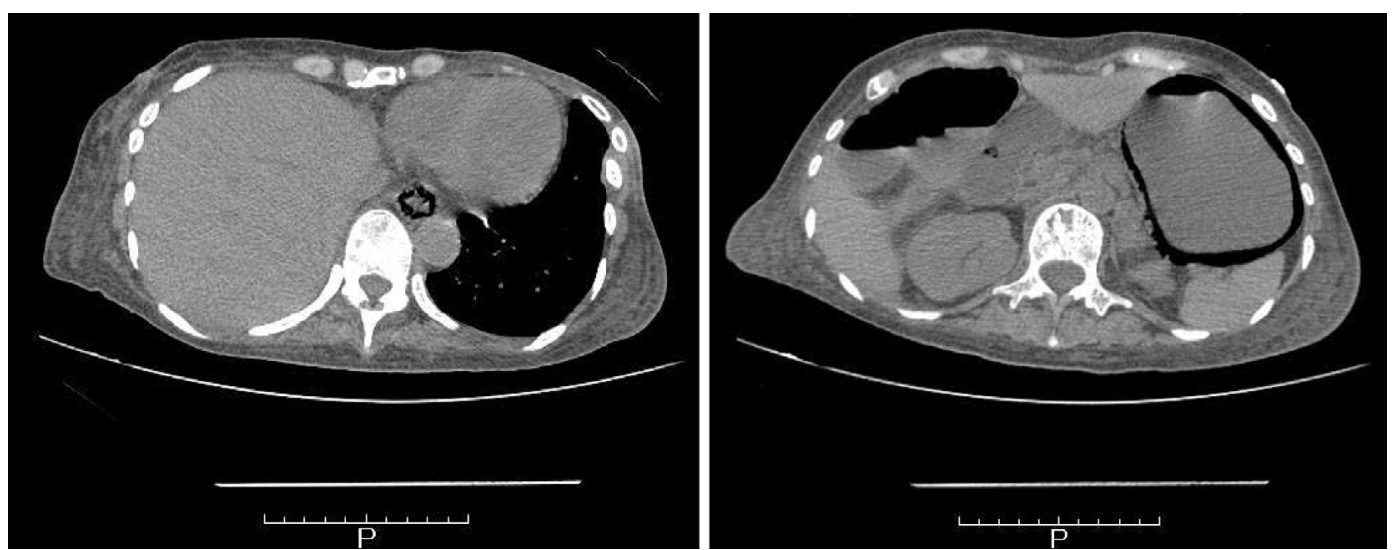

Picture 2.

A 62-year-old woman receiving chemotherapy for postoperative recurrent breast cancer visited our outpatient department with repeated vomiting, diarrhea and abdominal pain. The patient was admitted for acute gastroenteritis, and conservative therapy was started. In addition to an increased inflammatory reaction, a stool test was positive for Clostrid- ium difficile antigens; however, abdominal computed tomography (CT) showed no abnormalities. The patient's symptoms did not improve, and nine days after admission, thoracoabdominal radiographs (Picture 1) and CT images (Picture 2, 3) showed intramural gas (arrows) extending from the esophagus to the stomach. There was no free air in

${ }^{1}$ Multidisciplinary Treatment Cancer Center, Kurume University Hospital, Japan and ${ }^{2}$ Division of Gastroenterology, Department of Medicine, Kurume University School of Medicine, Japan

Received for publication November 4, 2014; Accepted for publication November 30, 2014

Correspondence to Dr. Mototsugu Matsunaga, mmandmacgyver@yahoo.co.jp 


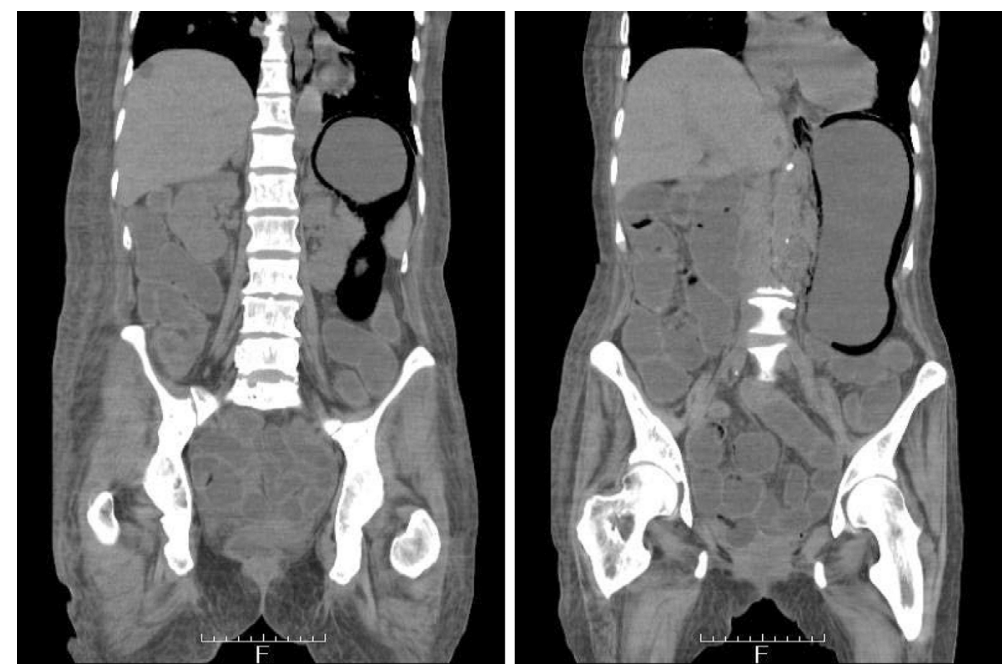

Picture 3.

the mediastinum or abdomen, and no metastasis of breast cancer to the gastric wall was detected. The patient died 14 days after admission.

We speculate that our patient was immunocompromised due to the effects of chemotherapy for recurrent breast cancer and subsequently experienced repeated vomiting as a result of gastrointestinal infection, which generated esophageal and gastric intramural gas associated with mechanical stimulation $(1,2)$.
The authors state that they have no Conflict of Interest (COI).

\section{References}

1. St Peter SD, Abbas MA, Kelly KA. The spectrum of pneumatosis intestinalis. Arch Surg 138: 68-75, 2003.

2. Majumder S, Trikudanathan G, Moezardalan K, Cappa J. Vomiting-induced gastric emphysema: a rare self-limiting condition. Am J Med Sci 341: 92-93, 2012.

(C) 2015 The Japanese Society of Internal Medicine http://www.naika.or.jp/imonline/index.html 